\title{
Complex function of the knee joint: the current understanding of the knee
}

\author{
Michael T. Hirschmann ${ }^{1} \cdot$ Werner Müller $^{1}$
}

Received: 18 March 2015 / Accepted: 27 April 2015 / Published online: 12 May 2015

(C) European Society of Sports Traumatology, Knee Surgery, Arthroscopy (ESSKA) 2015

\begin{abstract}
Since the early years of orthopaedics, it is a well-known fact that anatomy follows function. During the evolution of mankind, the knee has been optimally adapted to the forces and loads acting at and through the knee joint. However, anatomy of the knee joint is variable and the only constant is its complex function. In contrast to the time of open surgery, nowadays the majority of reconstructive knee surgery is done arthroscopically. Keyhole surgery is less invasive, but on the backside, the knee surgeon lacks daily visualisation of the complex open anatomy. As open anatomical knowledge is less present in our daily practice, it is even more important to highlight this complex anatomy and function of the knee. It is the purpose of this review to perform a systematic review of knee anatomy, highlight the complex function of the knee joint and present an overview about recent and current knowledge about knee function.
\end{abstract}

Level of evidence Systematic review, Level IV.

Keywords Knee - Anatomy - Function - ACL - PCL · Collaterals $\cdot$ MCL $\cdot$ LCL $\cdot$ Popliteus $\cdot$ ALL $\cdot$ Iliotibial tract

\section{Introduction}

Since the early years of orthopaedics, it is a well-known fact that anatomy follows function. During the evolution of

Michael T. Hirschmann

Michael.Hirschmann@unibas.ch

http://www.kneedoctor.ch

1 Department of Orthopaedic Surgery and Traumatology, Kantonsspital Baselland (Bruderholz, Liestal, Laufen), 4101 Bruderholz, Switzerland mankind, the knee has been optimally adapted to the forces and loads acting at and through the knee joint. However, anatomy of the knee joint is variable and the only constant is its complex function, which is the result of an optimal interplay of bony structures such as femur, tibia, patella and fibula as well as its ligaments, tendons, muscles and joint capsule [23]. There are only few anatomical structures that are solely responsible for one specific function [23]. Generally, each function of the knee is the result of a complex teamwork of several anatomical structures together [23].

The knee joint consists of the medial tibiofemoral, the lateral tibiofemoral, the patellofemoral and the proximal tibiofibular joint. A number of ligaments provide passive stability in all directions to the knee joint. In our daily activities, the knee carries a large portion of our body weight, allowing a wide range of motion for flexion-extension and internal-external rotation. The knee joint is a trochoginglymos, meaning a gliding hinge joint. The main principle of knee joint kinematics is rolling, gliding and rotation. The knee joint offers a six degrees of freedom range of motion. Rotational movement consists of flexion-extension, internal-external and varus-valgus. Translational movement is possible in anterior-posterior and medial-lateral direction as well as by compression and distraction of the knee joint (Fig. 1). All these six freedoms of motion are in combined complex function within the envelope of motion [27].

In the sagittal plane, rolling and gliding are the main elements. Menschik described the crossed four-bar linkage system as basic element of knee kinematics in 1974 (Figs. 2, 3) [21], a study which has inspired and highly impacted the way of thinking about knee kinematics for generations of knee surgeons.

In this system, the central pivot is build by the anterior and posterior cruciate ligaments as well as the meniscofemoral ligaments [23]. Clearly, the cruciates act as a gear and 
Fig. 1 Knee joint has six degrees of freedom for rotation and translation

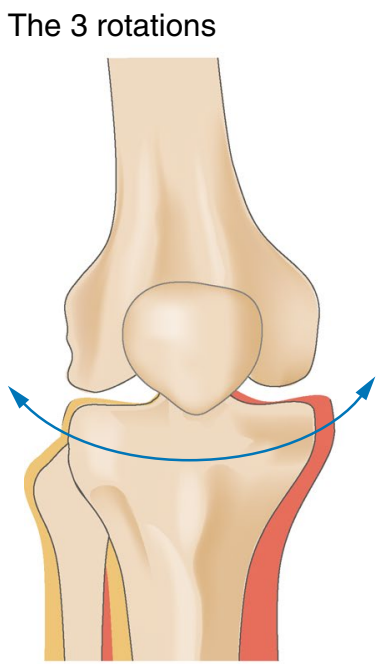

The 3 translations

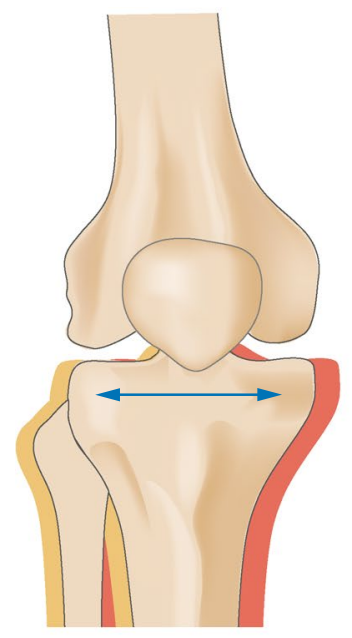

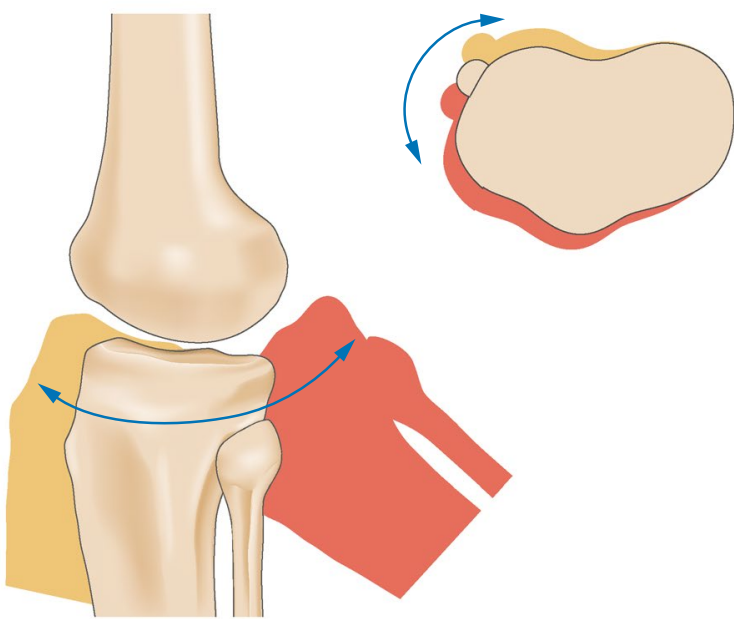

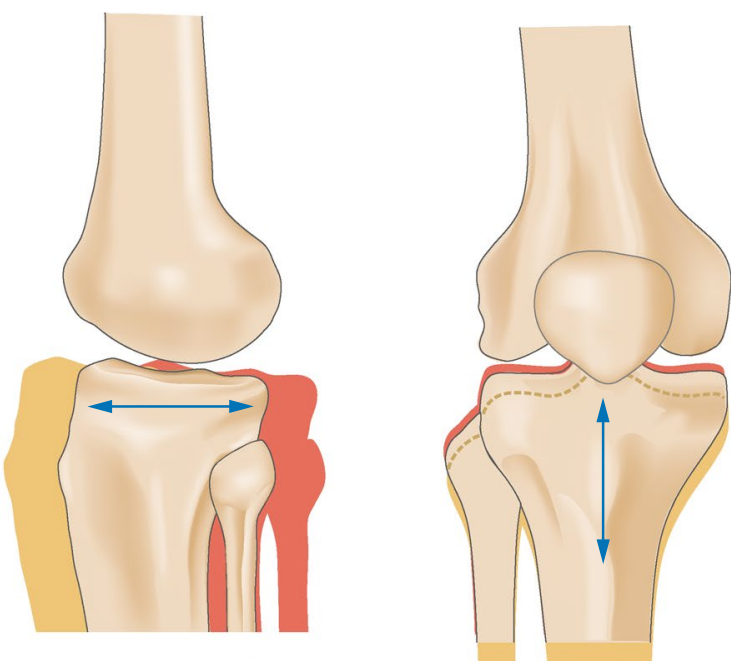

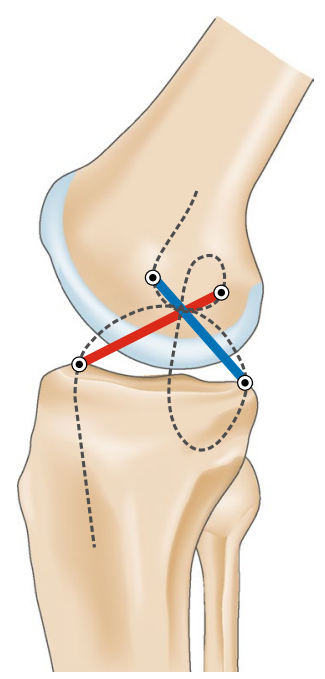

Fig. 2 Illustration of the Burmester curve and four-bar linkage system. The anterior and posterior cruciate ligaments represent the gear enabling the femur rolling and gliding on the tibia the menisci with their capsular attachments as a peripheral force control and brake system, called the enlarged central pivot (Fig. 7) [23]. The menisci act over an extended lever arm and guide rotational stability of the knee towards the periphery [23]. Both menisci insert on and around the intercondylar eminence and have fibre connections with the ACL and PCL [23]. The peripheral ligaments such as the collaterals are primary passive stabilisers against varusvalgus rotation as well as internal and external rotation [23]. Other peripheral structures are connected to tendons and can be actively dynamised when needed [23].

The range of motion of the knee joint is determined by the orientation of the femoral insertion of the crossed fourbar linkage system, meaning the femoral insertion of the cruciates [23]. Taking the principle of the four-bar linkage system into consideration, the femoral insertion of the cruciates needs to be at a $40^{\circ}$ angle to the femoral shaft axis [23]. It has been also observed that the roof of the notch is oriented $40^{\circ}$ towards the femoral shaft axis (Fig. 4). 
a

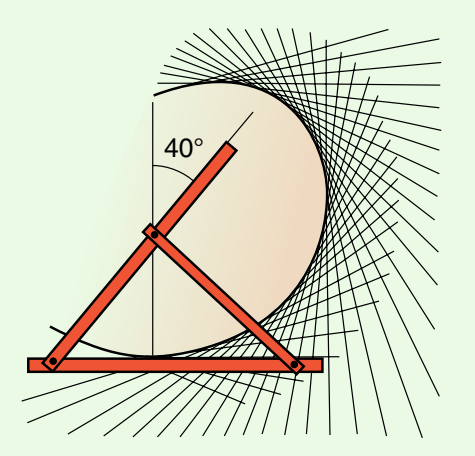

b

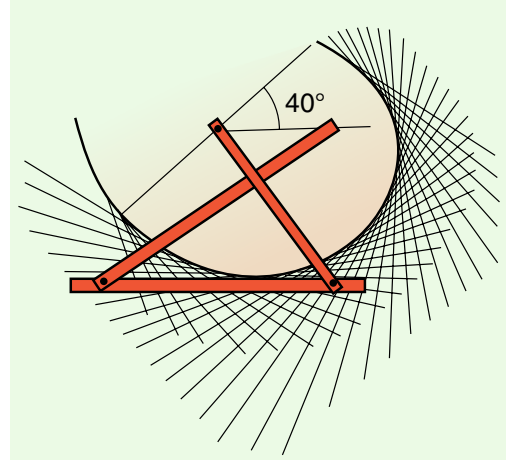

C

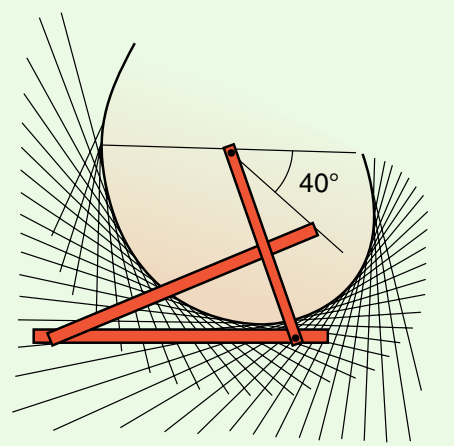

d

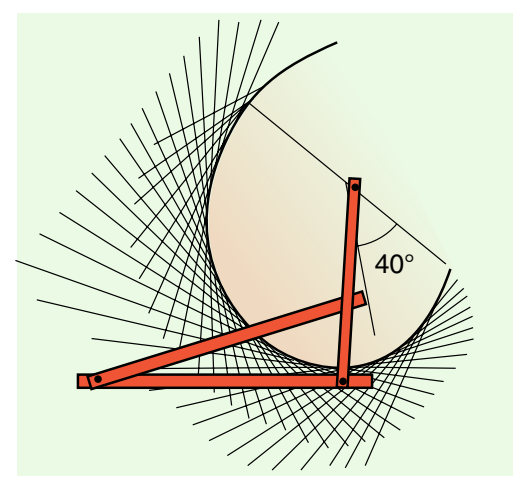

e

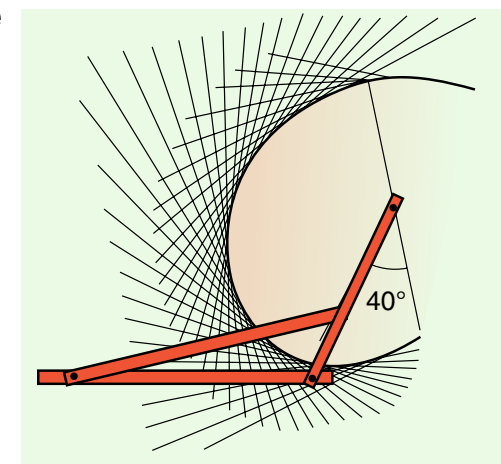

Fig. 3 Four-bar linkage system at different degrees of flexion

Fig. 4 Illustration showing the concept of isometry with regard to different ACL insertion sites. A anteriorly placed ACL (a) is too loose in $40^{\circ}$ flexion (b) and too tight in $120^{\circ}$ flexion $(\mathbf{c})$

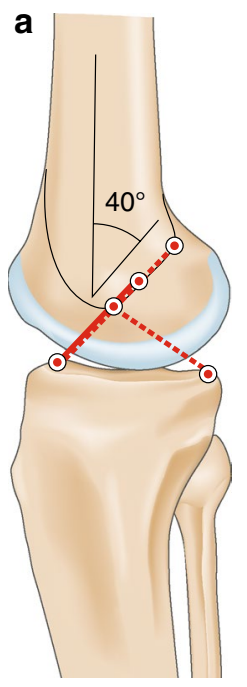

Generally, the Burmester curve is the most important biomechanical principle which has to be considered when repairing or reconstructing a torn ligament. For each knee, all repaired or reconstructed ligaments need to be on the ideal path of the Burmester curve, otherwise they will fail or elongate. For a better understanding, the concept of isometry and anisometry has to be briefly explained. Isometry is found when a ligament does not change its length

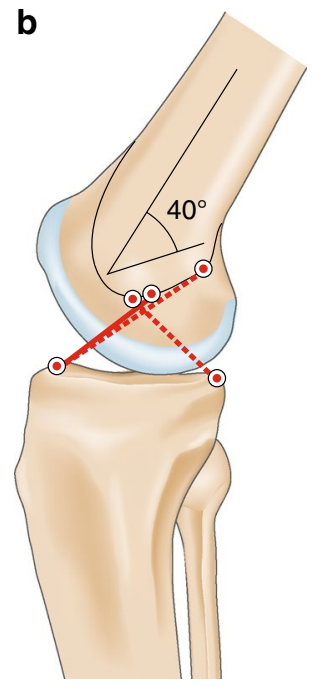

C

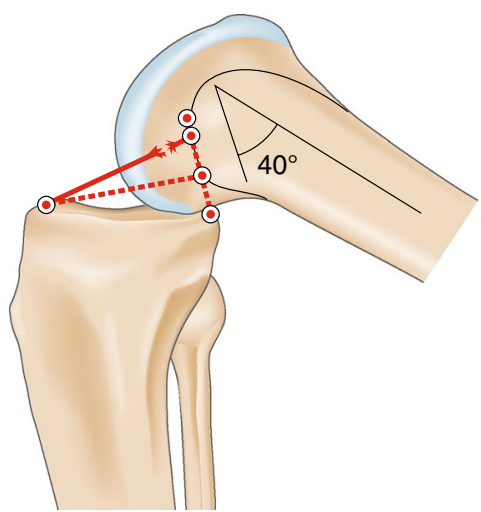

during flexion-extension. Anisometry is the opposite finding. The core of the ACL is considered to be isometric.

The concept of isometry is shown in Fig. 4. Here a nonanatomical ACL insertion point leads to increased ACL strain and length change. In the case of too much length change, the ACL graft fails.

The native anatomy of the knee follows these biomechanical considerations. Hence these should build the basis 
for surgical reconstruction of injured knee structures. In the past, we have learned why knee reconstructions failed. One major reason was non-anatomical reconstructive procedures. Restoration of anatomy is the most important key for knee surgery and cannot be overestimated. Only if the surgeon knows what normal anatomy is, anatomy can be restored in the injured knee.

Anatomy of the knee is the basis for its function and hence it is the purpose of the following review to describe relevant knee anatomy and explain knee kinematics with regard to its complex function in detail.

\section{The central pivot}

The cruciates are probably the best studied anatomical structure in the human body $[2,5-7,9,12,15,18-20,28$, 30, 31, 33, 35-38, 41, 46, 47]. A tear of the ACL disrupts the four-bar linkage system and disturbs the rolling gliding mechanism $[23,24]$. In the case of an ACL tear, the femoral condyle rolls too far backwards and then snaps forwards into the demanded corrected physiologic position [23]. Clearly, the pivot shift test represents an anterior tibial subluxation that occurs when the ACL is insufficient. In early flexion, the anterolateral quadrant of the tibia is anteriorly translated by internal rotation and valgus force. The subsequent reduction in the tibia is due to the iliotibial tract and occurs with a clunk when the knee is flexed $20^{\circ}-40^{\circ}$. The first description of the kinematic explanation of the pivot shift was given in 1977 by Müller [25]. The pivot shift mechanism can be better explained when the relationship with the aforementioned four-bar linkage mechanism is understood. Just recently, the pivot shift mechanism has been postulated to represent an injury of the anterolateral capsule, newly named anterolateral ligament (ALL) [3, 4].

In the last years, ACL anatomy has been rediscovered. After the era of transtibial non-anatomical ACL surgery, double-bundle reconstruction has turned the focus from purely technical back to anatomical considerations. However, ACL anatomy was still simplified. The ACL was then considered to have two or even three functional main bundles: the anteromedial (AM), posterolateral (PL) and intermediate bundle (IM). These bundles are named with regard to their tibial insertions [30, 34, 43]. The cross-sectional shape of the ACL is considered to be "irregular" rather than circular, elliptical or any other simple geometric form. The shape is variable with the angle of flexion. Kinematically the AM bundle is tight during knee flexion, and the PL bundle is tight during knee extension and knee internal rotation [43]. The orientation of the ACL bundle attachment sites changes as the knee flexes. In extension, the origin of the AM bundle is located just above the origin of the PL bundle. When the knee is flexed, the attachment site of the AM bundle moves behind the PL bundle origin [48].

The femoral insertion site of the ACL is semilunar. It shows an attachment length of 13-25 mm and a width of 6-13 mm [39, 40]. Others found a more circular or oval shape of the ACL attachment site [48].

Today, the ACL double-bundle differentiation is a matter of debate. A recent very well-performed MRI and cadaveric dissection study by Smigielski et al. [36] showed no clear ACL bundle structure. This detailed anatomical study found a ribbon-like structure of the ACL from its femoral insertion to midsubstance [36]. From a total of 2-3 mm from its bony femoral insertion, the ACL formed a flat ribbon without a clear separation between AM and PL bundles [36]. The ribbon was in exact continuity of the posterior femoral cortex [36].

The burning question remaining is, "How many bundles actually form the ACL?" One bundle, two bundles, two bundles with an intermediate third bundle or 6-10 fibre bundles? Clinically this question is important, as the function of the ACL can be replicated only if the complex structural network of collagen fibres and its function are understood.

Mommersteg et al. [22] found 6-10 bundles and multiple fascicles. The ACL fibres of the ACLs fan out towards the femoral and tibial insertion, meaning that the ACL is narrower at midpoint and wider near the insertion site [22].

Friederich and O'Brien investigated the length change patterns of ACL fibre trajectories during extension and flexion. They outlined a system of progressive ACL fibre recruitment during flexion-extension [8]. In knee flexion, the position of the ACL is almost horizontal [8]. Then, less fibres are acting against anterior translation as the leaver arm is long [8]. In knee extension, the ACL is more vertical, its leaver arm is shorter and all fibres are now recruited (Figs. 5, 6). This fact is important because the length of the ACL changes with varying degrees of knee flexion, meaning that it is mostly not isometric [48]. The consequence of this finding is that even a slight variation of the femoral tunnel potentially has a strong effect on the length and tension of the ACL [48] (Fig. 7).

Clearly, the non-isometry and multiple fibre structure of the ACL are the key factors for ACL reconstruction. An optimal ACL reconstruction should kinematically, biologically and anatomically restore the native ACL. In the early years of ACL reconstruction, we started to perform anatomical single-bundle ACL reconstruction and did not change the technique for 20 years. Ten years ago, we changed the technique to a double-incision iso-anatomical ACL reconstruction using bone-patellar tendon-bone autograft $[1,10]$. However, the tunnel position was always anatomical and never changed. Future challenge of ligament reconstruction is to restore joint homoeostasis. 

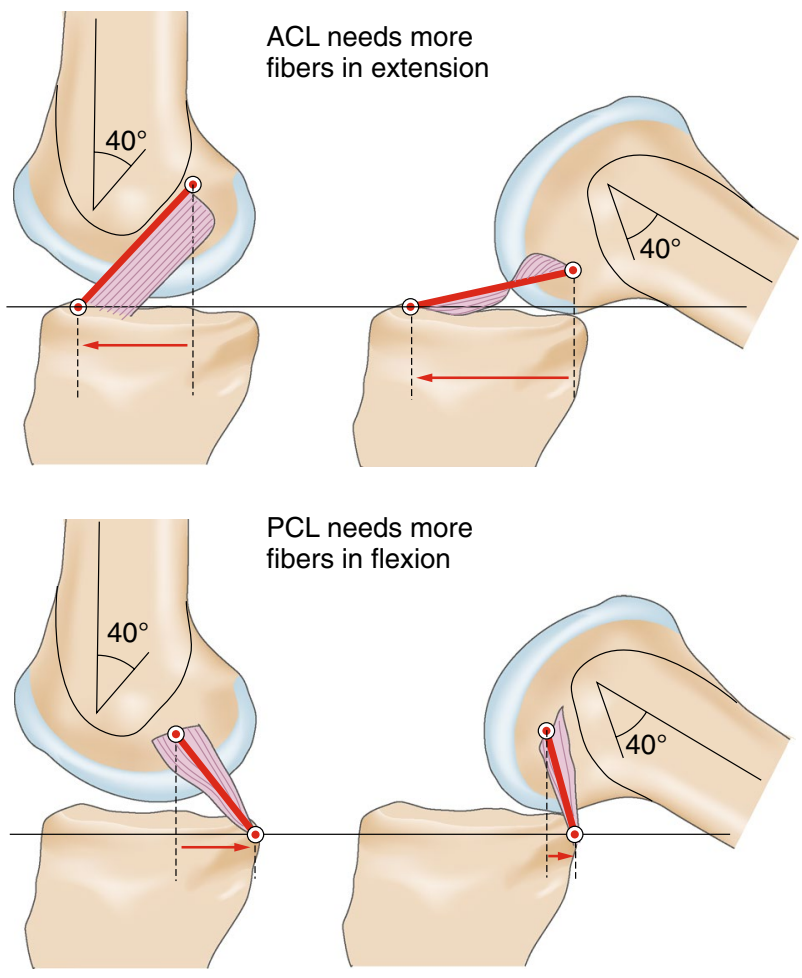

Fig. 5 Recruitment of fibres for ACL and PCL with regard to extension or flexion

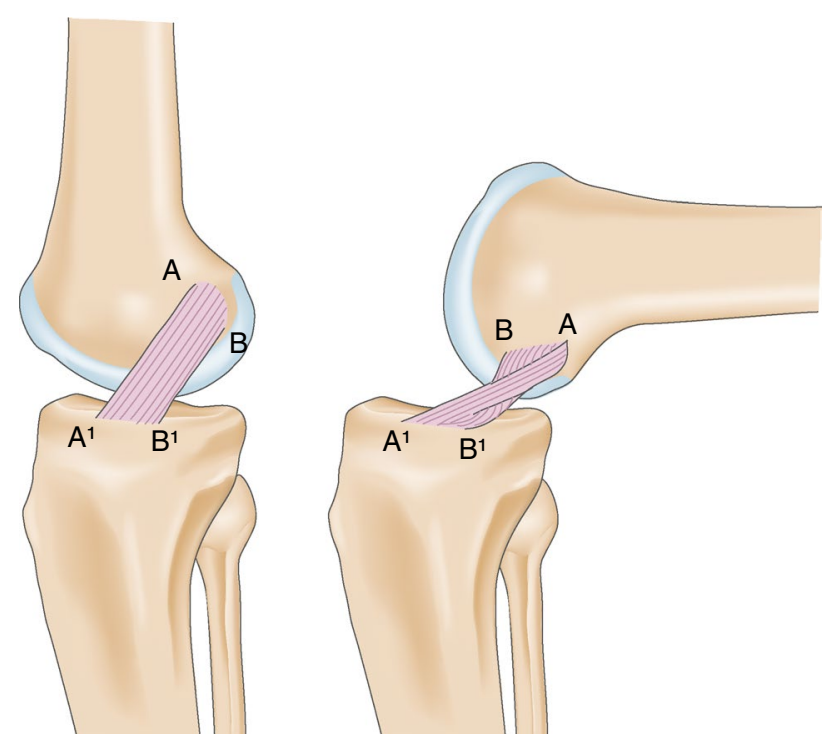

Fig. 6 Illustration of the ACL showing the tibial and femoral attachments and the course of ACL in flexion and extension

The posterior cruciate ligament (PCL) has been less intensively investigated than the ACL, but the above-mentioned principles also apply to the PCL.

The PCL is the strongest ligament of the knee and consists of multiple bundles; most authors believe $2-3$ bundles:

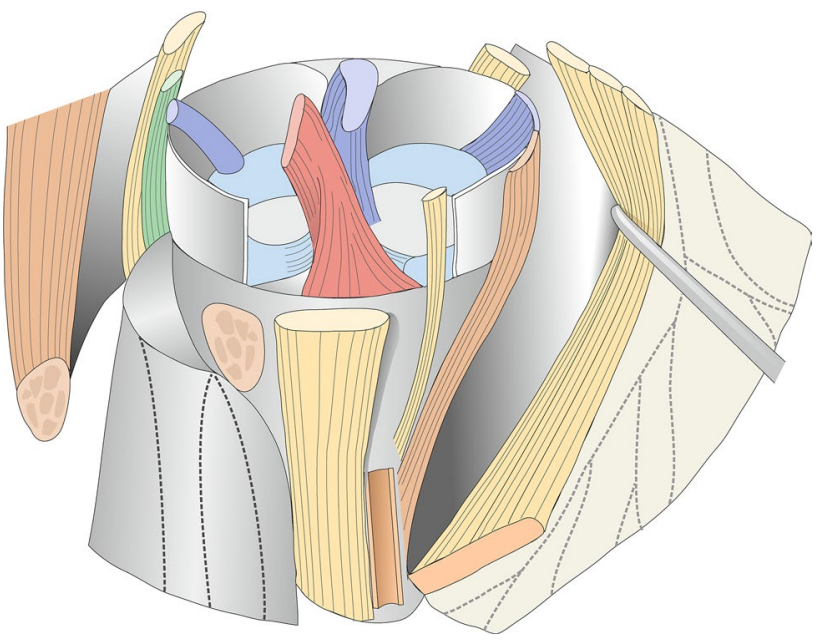

Fig. 7 Illustration showing the central pivot, ACL and PCL enlarged with the medial and lateral menisci

the anterolateral (ALB), the posteromedial (PMB) and the intermediate bundles. However, again Mommersteg et al. [22] found 6-10 bundles and multiple fascicles. Both the lengths and the widths of the PCLs are larger than those of the ACL.

The PCL is the primary restraint to posterior tibial translation and a secondary restraint to external tibial rotation [17, 45]. Both PCL bundles have a stabilizing function in terms of posterior translation throughout the full range of knee flexion $[17,45]$. Although the ALB is the predominant restraint to posterior translation from $15^{\circ}$ to $90^{\circ}$, the PMB also has a supplemental role at these angles [17, 45]. The PCL also restricts internal rotation at all ranges of flexion $[17,45]$. The PMB plays a role in preventing internal rotation beyond $90^{\circ}$ of flexion $[17,45]$. The entire PCL has a small but significant role in restricting tibial internal and external rotations, particularly beyond $90^{\circ}$ of flexion $[17,45]$.

\section{Menisci}

The menisci form a mobile containment on the tibial plateau adapting to the rolling gliding and rotating movement of the femoral condyles [16]. The incongruity of femoral condyle and tibial plateau is compensated by the medial and lateral meniscus [16]. Both menisci are fixed to the peripheral capsule, and the anterior and posterior roots are fixed to the tibial plateau [16]. At the capsule, an abundant number of free nerve endings are important for proprioception [16]. Both anterior roots of the menisci are connected with the transverse ligament, which is connected via small strains to the patellar tendon [16]. In addition, the medial meniscus is connected to the medial collateral ligament. The medial posterior horn is fixed to the posterior oblique ligament (POL) and functions as an important secondary 
co-restraint to the ACL and with its parallel orientation to the PCL also a co-restraint for the PCL [16]. The lateral meniscus is dynamised as well. The popliteus muscle directs its first tendon to insert widely into the posterior horn of the meniscus. When flexing the knee, the popliteus tendon pulls the lateral meniscus posteriorly.

During flexion, the contact point of femoral condyle and tibial plateau moves posteriorly [16]. The medial meniscus moves $6 \mathrm{~mm}$ posteriorly, the lateral one $12 \mathrm{~mm}$. During extension, it moves anteriorly [16]. The menisci follow the femoral condyle and tibial plateau [16]. In addition, both menisci are deformed, the lateral more than the medial meniscus [16].

According to Kapandji, it can be distinguished between active and passive factors influencing meniscus motion [16]. Passively the motion is determined by the femoral condyles that push the menisci back and forwards during flexion-extension [16].

Active factors are the following: extending the knee, the menisci are pulled forwards by fibres, which connect the patella and the anterior menisci as well as the transverse ligament [16]. The meniscofemoral ligament also pulls the menisci forwards [16]. Flexing the knee, the medial meniscus is pulled backwards by the semimembranosus tendon, the lateral meniscus by contraction of the popliteus tendon [16]. There is also a coupled motion of menisci and the tibiofemoral joint. In external tibial rotation, the lateral meniscus is pulled anteriorly, the medial meniscus posteriorly [16]. In internal tibial rotation, the lateral meniscus is pulled posteriorly, the medial meniscus anteriorly [16]. This above-described coupled motion of the menisci explains vulnerability of the menisci during rotational movements. The lateral meniscus is much more mobile than the medial one. At one hand, this is reflected by the higher rate of medial meniscus tears, as the fixed meniscus is less able to compensate for rotational and forces and on the other hand, as the lateral compartment is the mobile knee compartment, a lateral meniscectomy is more devastating than a medial meniscectomy leading to a more rapid development of OA [11, 29]. In addition, also short-term outcomes after lateral partial meniscectomy are worse [26]. According to a recent study, time to return to play for an elite soccer player is 7 weeks after a partial lateral meniscectomy, compared with 5 weeks after a partial medial meniscectomy [26]. The rate of returning to play was 5.99 times greater for players with a partial medial meniscectomy [26].

\section{Medial knee compartment: the stable one}

The medial compartment is tightly fixed between the two strongest ligaments, the PCL and the medial collateral ligament system, including the POL with the meniscus [23].
Therefore, there is less rotation excursion on this side and the axis of internal-external rotation stays in this medial compartment [23]. The medial knee compartment can be called the stable knee compartment.

The medial collateral ligament (MCL) is tight in extension and loose in flexion [23]. It is also tightened in external rotation and loose in internal rotation [23]. During flexion, the posterior part of the MCL is folded under the anterior part of the MCL. A complex system of progressive fibre recruitment towards extension when more force for the resistance against valgus is necessary can be observed [23].

For many years, there were problems in stabilizing chronic medial valgus instabilities until it was recognised that the two main semimembranosus tendons, the pars directa and the pars reflexa, were injured in these cases.

The most important and strongest protector against valgus and external rotation is the semimembranosus with its insertion close to the POL on the tibia and with its five tendon arms, two to the tibia, one to the POL-medial meniscus, one as lig. popliteum obliquum (oblique popliteal ligament) to the fabella and the fifth into the aponeurosis of the popliteus muscle. It controls the posteromedial stability from an ideal position in all directions. In extension, the pars directa goes to the posterior tibial crest stabilizing against valgus. In flexion, the pars reflexa passing under the MCL is the most important restraint of internal rotation.

\section{Lateral compartment: the mobile one}

In contrast to the medial knee compartment, the lateral one can be called the mobile knee compartment. This is due to the fact that the axis of rotation is based in the medial compartment. As a consequence, the lateral compartment has no distinct ligament, which directly connects the tibia and the femur, as this would imply too much length change during extension-flexion and external-internal rotation. The later mentioned ALL should be better seen as thickening of the lateral capsule.

The lateral collateral ligament (LCL) runs from the femur to the fibula, as the proximal tibiofibular joint allows the necessary adaption for the needed length change during flexion-extension. The biceps tendon tightens the LCL by its course around the ligament. The LCL represents a good example of a dynamised ligament, meaning that by contraction of the biceps tendon, the LCL is actively tightened.

The popliteus system is dynamically stabilising the lateral knee compartment. It has three tendon arms and acts as a primary static stabiliser to external rotation. The first tendon arm, which consists of synovial reflections above and below the meniscus, also known as popliteomeniscal fascicles, is directed towards the posterior wall of the lateral 
meniscus [42]. The second one represents the popliteofibular ligament, which connects the fibular head and the popliteus tendon [42]. It is the thickest part of the popliteus system. The third tendon arm runs underneath the LCL to its insertion, which is slightly ventral and distal to the femoral LCL insertion [42].

A torn popliteofibular ligament leads to increased rotational freedom of the popliteus tendon. In such a case, the popliteus tendon is unconstrained from the popliteofibular ligament restraints and approximately $1 \mathrm{~cm}$ longer allowing more tibial rotation [42].

The popliteus muscle belly lies on the medial backside of the proximal tibia. With its tendon, it is an important internal rotator and an important secondary restraint to the PCL. The popliteal aponeurosis is closely interwoven with tendon fibres of the semimembranosus muscle, which creates a direct link between the posteromedial and the posterolateral structures.

The iliotibial tract (ITT) attaches at Gerdy's tubercle and functions as anterolateral stabiliser of the knee joint. Here the same principle of a dynamised structure can be found (Fig. 8). The Kaplan fibres, which connect the ITT with the distal lateral femoral condyle, represent a dynamic ligamentous junction. It diverts the strong forces of the tensor fasciae latae and glutaeus maximus muscles. The posterior fibres of the ITT are almost isometric at flexion angles between $0^{\circ}$ and $50^{\circ}$. Between $50^{\circ}$ and $90^{\circ}$ flexion, the posterior fibres of ITT decrease in length. The anterior fibres of the ITT increase in length between $0^{\circ}$ and $40^{\circ}$ of flexion and were then almost isometric from $40^{\circ}$ to $90^{\circ}$.

Recently, the importance of the ALL has been rediscovered. Segond was the first to mention a capsular avulsion at the lateral tibia [32]. In addition, in early textbooks and

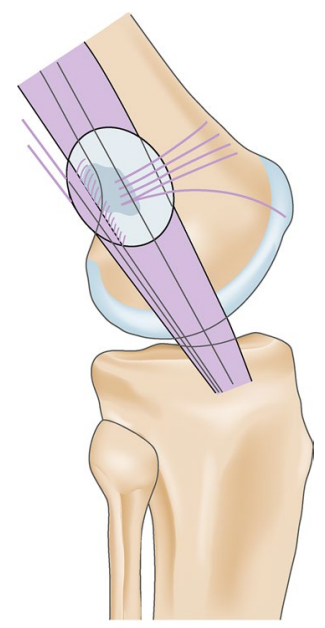

Fig. 8 Illustration showing the Kaplan fibres of the iliotibial tract originating at the lateral distal femur dynamising this important structure publications, it has been already mentioned as capsuloligamentous thickening of the anterolateral capsule or the mid-third capsular ligament [13, 14, 23]. However, its clear function and anatomical description have been vague and inconsistent. The origin of the ALL is on the lateral femoral epicondyle proximal and posterior to the popliteus tendon insertion [44]. It inserts on the lateral meniscus and tibia $5 \mathrm{~mm}$ distal to the tibiofemoral joint and posterior to Gerdy's tubercle [44]. The ALL is most tight during combined flexion and internal tibial rotation. Hence it serves as stabiliser for internal rotation [44].

\section{Conclusion}

This review of complex knee function is not the sole truth, but it represents the current state of error. This is one way to understand the complex knee function.

To date, there is a great amount of scientific data and anatomical information available, but one has to translate this knowledge into surgical reality. This is possible only with a profound understanding of complex knee function and kinematics.

\section{References}

1. Arnold MP, Duthon V, Neyret P, Hirschmann MT (2013) Double incision iso-anatomical ACL reconstruction: the freedom to place the femoral tunnel within the anatomical attachment site without exception. Int Orthop 37:247-251

2. Arnold MP, Kooloos J, van Kampen A (2001) Single-incision technique misses the anatomical femoral anterior cruciate ligament insertion: a cadaver study. Knee Surg Sports Traumatol Arthrosc 9:194-199

3. Claes S, Luyckx T, Vereecke E, Bellemans J (2014) The Segond fracture: a bony injury of the anterolateral ligament of the knee. Arthroscopy 30:1475-1482

4. Claes S, Vereecke E, Maes M, Victor J, Verdonk P, Bellemans J (2013) Anatomy of the anterolateral ligament of the knee. J Anat 223:321-328

5. Feagin JA Jr, Curl WW (1976) Isolated tear of the anterior cruciate ligament: 5-year follow-up study. Am J Sports Med 4:95-100

6. Felmet G (2010) Implant-free press-fit fixation for bone-patellar tendon-bone ACL reconstruction: 10-year results. Arch Orthop Trauma Surg 130:985-992

7. Friederich NF (1993) Knee joint function and the cruciate ligaments. Biomechanical principles for reconstruction and rehabilitation. Orthopade 22:334-342

8. Friederich NF, Muller W, O'Brien WR (1992) Clinical application of biomechanic and functional anatomical findings of the knee joint. Orthopade 21:41-50

9. Fu FH, Ranawat A (2007) Tensioning in double-bundle ACL reconstruction. Arthroscopy 23:1027-1028

10. Gerhard P, Bolt R, Duck K, Mayer R, Friederich NF, Hirschmann MT (2013) Long-term results of arthroscopically assisted anatomical single-bundle anterior cruciate ligament reconstruction using patellar tendon autograft: are there any predictors for the development of osteoarthritis? Knee Surg Sports Traumatol Arthrosc 21:957-964 
11. Haviv B, Bronak S, Kosashvili Y, Thein R (2015) Which patients are less likely to improve during the first year after arthroscopic partial meniscectomy? A multivariate analysis of 201 patients with prospective follow-up. Knee Surg Sports Traumatol Arthrosc. doi:10.1007/s00167-015-3590-Z

12. Hertel P, Behrend H, Cierpinski T, Musahl V, Widjaja G (2005) ACL reconstruction using bone-patellar tendon-bone press-fit fixation: 10-year clinical results. Knee Surg Sports Traumatol Arthrosc 13:248-255

13. Hughston JC, Andrews JR, Cross MJ, Moschi A (1976) Classification of knee ligament instabilities. Part I. The medial compartment and cruciate ligaments. J Bone Joint Surg Am 58:159-172

14. Hughston JC, Andrews JR, Cross MJ, Moschi A (1976) Classification of knee ligament instabilities. Part II. The lateral compartment. J Bone Joint Surg Am 58:173-179

15. Jarvela T, Suomalainen P (2011) ACL reconstruction with double-bundle technique: a review of clinical results. Phys Sportsmed 39:85-92

16. Kapandji IA (1999) Funktionelle Anatomie der Gelenke, vol 2. Hippokrates Verlag GmbH, Stuttgart, Untere Extremität

17. Kennedy NI, Wijdicks CA, Goldsmith MT, Michalski MP, Devitt BM, Aroen A, Engebretsen L, LaPrade RF (2013) Kinematic analysis of the posterior cruciate ligament, part 1: the individual and collective function of the anterolateral and posteromedial bundles. Am J Sports Med 41:2828-2838

18. Kohl S, Evangelopoulos DS, Kohlhof H, Hartel M, Bonel H, Henle P, von Rechenberg B, Eggli S (2013) Anterior crucial ligament rupture: self-healing through dynamic intraligamentary stabilization technique. Knee Surg Sports Traumatol Arthrosc 21:599-605

19. Kondo E, Merican AM, Yasuda K, Amis AA (2010) Biomechanical comparisons of knee stability after anterior cruciate ligament reconstruction between 2 clinically available transtibial procedures: anatomic double bundle versus single bundle. Am J Sports Med 38:1349-1358

20. Lind M, Menhert F, Pedersen AB (2009) The first results from the Danish ACL reconstruction registry: epidemiologic and 2 year follow-up results from 5818 knee ligament reconstructions. Knee Surg Sports Traumatol Arthrosc 17:117-124

21. Menschik A (1974) Mechanik des Kniegelenkes. Z Orthop 112:481-495

22. Mommersteeg TJ, Kooloos JG, Blankevoort L, Kauer JM, Huiskes R, Roeling FQ (1995) The fibre bundle anatomy of human cruciate ligaments. J Anat 187:461-471

23. Mueller W (1982) The knee: form, function, and ligament reconstruction. Springer, New York

24. Muller W (1977) Current aspects of functional anatomy of the knee joint. Hefte Unfallheilkd 129:131-137

25. Müller W (1977) Verletzungen der Kreuzbänder. Zentralbl Chir 102:974-981

26. Nawabi DH, Cro S, Hamid IP, Williams A (2014) Return to play after lateral meniscectomy compared with medial meniscectomy in elite professional soccer players. Am J Sports Med 42:2193-2198

27. Noyes FR, Cummings JF, Grood ES, Walz-Hasselfeld KA, Wroble RR (1991) The diagnosis of knee motion limits, subluxations, and ligament injury. Am J Sports Med 19:163-171

28. O'Donoghue DH (1950) Surgical treatment of fresh injuries to the major ligaments of the knee. J Bone Joint Surg Am 32:721-738

29. Pena E, Calvo B, Martinez MA, Palanca D, Doblare M (2006) Why lateral meniscectomy is more dangerous than medial meniscectomy. A finite element study. J Orthop Res 24:1001-1010

30. Purnell ML, Larson AI, Clancy W (2008) Anterior cruciate ligament insertions on the tibia and femur and their relationships to critical bony landmarks using high-resolution volume-rendering computed tomography. Am J Sports Med 36:2083-2090

31. Schindler OS (2012) Surgery for anterior cruciate ligament deficiency: a historical perspective. Knee Surg Sports Traumatol Arthrosc 20:5-47

32. Segond P (1879) Recherches cliniques et expérimentales sur les épanchements sanguins du genou par entorse. Prog Med (Paris) 7:297-299, 319-321, 340-341

33. Siebold R (2011) The concept of complete footprint restoration with guidelines for single- and double-bundle ACL reconstruction. Knee Surg Sports Traumatol Arthrosc 19:699-706

34. Siebold R, Ellert T, Metz S, Metz J (2008) Tibial insertions of the anteromedial and posterolateral bundles of the anterior cruciate ligament: morphometry, arthroscopic landmarks, and orientation model for bone tunnel placement. Arthroscopy 24:154-161

35. Siebold R, Schuhmacher P, Fernandez F, Smigielski R, Fink C, Brehmer A, Kirsch J (2014) Flat midsubstance of the anterior cruciate ligament with tibial "C"-shaped insertion site. Knee Surg Sports Traumatol Arthrosc. doi:10.1007/s00167-014-3058-6

36. Smigielski R, Zdanowicz U, Drwiega M, Ciszek B, Ciszkowska-Lyson B, Siebold R (2014) Ribbon like appearance of the midsubstance fibres of the anterior cruciate ligament close to its femoral insertion site: a cadaveric study including 111 knees. Knee Surg Sports Traumatol Arthrosc. doi:10.1007/ s00167-014-3146-7

37. Sonnery-Cottet B, Lavoie F, Ogassawara R, Scussiato RG, Kidder JF, Chambat P (2010) Selective anteromedial bundle reconstruction in partial ACL tears: a series of 36 patients with mean 24 months follow-up. Knee Surg Sports Traumatol Arthrosc 18:47-51

38. Steadman JR, Cameron-Donaldson ML, Briggs KK, Rodkey WG (2006) A minimally invasive technique ("healing response") to treat proximal ACL injuries in skeletally immature athletes. J Knee Surg 19:8-13

39. Steckel H, Musahl V, Fu FH (2010) The femoral insertions of the anteromedial and posterolateral bundles of the anterior cruciate ligament: a radiographic evaluation. Knee Surg Sports Traumatol Arthrosc 18:52-55

40. Steckel H, Starman JS, Baums MH, Klinger HM, Schultz W, Fu FH (2007) Anatomy of the anterior cruciate ligament double bundle structure: a macroscopic evaluation. Scand J Med Sci Sports 17:387-392

41. Tashman S, Kopf S, Fu FH (2008) The kinematic basis of ACL reconstruction. Oper Tech Sports Med 16:116-118

42. Thaunat M, Pioger C, Chatellard R, Conteduca J, Khaleel A, Sonnery-Cottet B (2014) The arcuate ligament revisited: role of the posterolateral structures in providing static stability in the knee joint. Knee Surg Sports Traumatol Arthrosc 22:2121-2127

43. Tsukada H, Ishibashi Y, Tsuda E, Fukuda A, Toh S (2008) Anatomical analysis of the anterior cruciate ligament femoral and tibial footprints. J Orthop Sci 13:122-129

44. Vincent JP, Magnussen RA, Gezmez F, Uguen A, Jacobi M, Weppe F, Al-Saati MF, Lustig S, Demey G, Servien E, Neyret $P$ (2012) The anterolateral ligament of the human knee: an anatomic and histologic study. Knee Surg Sports Traumatol Arthrosc 20:147-152

45. Wijdicks CA, Kennedy NI, Goldsmith MT, Devitt BM, Michalski MP, Aroen A, Engebretsen L, LaPrade RF (2013) Kinematic analysis of the posterior cruciate ligament, part 2: a comparison of anatomic single- versus double-bundle reconstruction. Am J Sports Med 41:2839-2848

46. Zaffagnini S, Bruni D, Russo A, Takazawa Y, Lo Presti M, Giordano G, Marcacci M (2008) ST/G ACL reconstruction: double strand plus extra-articular sling versus double bundle, randomized study at 3-year follow-up. Scand J Med Sci Sports $18: 573-581$ 
47. Zantop T, Diermann N, Schumacher T, Schanz S, Fu FH, Petersen W (2008) Anatomical and nonanatomical doublebundle anterior cruciate ligament reconstruction: importance of femoral tunnel location on knee kinematics. Am J Sports Med 36:678-685
48. Zantop T, Petersen W, Sekiya JK, Musahl V, Fu FH (2006) Anterior cruciate ligament anatomy and function relating to anatomical reconstruction. Knee Surg Sports Traumatol Arthrosc 14:982-992 